Bangladesh J. Sci. Res. 26(1\&2): 37-46, 2013 (December)

\title{
FACTORS DIVIDE FERTILITY BETWEEN EAST AND WEST AREAS OF BANGLADESH: IMPLICATIONS FOR FURTHER STRENGTHENING THE FAMILY PLANNING PROGRAM
}

\author{
M. Sheikh Giash Uddin*, Md. Abul Kalam Azad and M. G. Kibria ${ }^{1}$ \\ Department of Statistics, Jagannath University, Dhaka-1100, Bangladesh
}

\begin{abstract}
Bangladesh Demographic and Health Survey data were used for the study. The results suggest that women in the East have an average of 2.34 living children compared to an average of 1.83 living children in the West. Women with all living female children are two times more likely to give births than women having at least one male child in the East. Sex preference is an important determinant of current use of contraception in Bangladesh. In the East, women with two sons are 1.9 times more likely to use contraception than women with two daughters. Current use of contraception divides the East and West for fertility differential. It also implies that the reduction in fertility may largely depend on increased use of effective birth control methods in future in Bangladesh.
\end{abstract}

Key words: Fertility, family planning, sex preference

\section{Introduction}

Bangladesh has achieved a considerable decline in fertility from high 6.3 births per woman in 1971-75 to 2.3 births per woman in 2011. Several researchers argued that this fertility decline in Bangladesh was achieved primarily due to a successful family planning program (Cleland 1994, Caldwell et al. 1999, Kabir and Chowdhury 2004, Mamun et al. 1998 and Islam et al. 2004). There are substantial variations in the level of fertility among the six divisions. Khulna (South West) division achieved replacement level fertility in 2007. The fertility levels are rather uneven with large socio-economic and geographic differences. But the largest differential is across divisions, with higher fertility in the East part (Chittagong and Sylhet divisions) than the West part (Khulna and Rajshahi divisions) of the country. In 2007, women in Sylhet division had on the average 1.7 more children than women in Khulna division and also the women in Chittagong division had 1.2 more children than that of Khulna division (NIPORT et al. 2009). Khulna and Rajshahi divisions which we labeled as West exhibit consistently low levels of fertility and high levels of contraceptive prevalence rates as against Chittagong and Sylhet labeled as East which show consistently high levels of fertility and low levels of contraceptive use.

The decline in fertility in Bangladesh during 1980s and early 1990s were well documented. However, during the period 1993-94 to 1999-2000 fertility remained stagnant despite increase in the current contraceptive use. Cleland (1994) argued that the past $d$ ecline in the level of fertility

\footnotetext{
*Corresponding author: <giash16@gmail.com>. ${ }^{1}$ Management Sciences for Health (MSH), Gulshan, Dhaka-1212, Bangladesh.
} 
was mainly attributed to a strong family planning program in the absence of any remarkable change in the socio-economic development. Another disturbing element in the level of fertility, as mentioned by Bongaarts and Feeney (1998), is that births either postponed by marrying later or births occurring either earlier or later than the previous cohorts can make the conventional TFR misleading. Bongaarts and Feeney (1998) showed that the conventional TFR is composed of two components attributable to quantum and tempo effects. Tempo effect is referred to the distortion caused by change in timing of births and the quantum effect is defined as the TFR that would have been observed in the absence of changes in the timing of child bearing during the period in which the TFR is measured (Bongaarts and Feeney 1998).

It has been found that delayed marriage can play an important role in reducing the level of fertility through reduction of child bearing span. However, the level of fertility appears to be a function of not only age at marriage, and hence age at first birth, but also on the intervals between subsequent births as well. It has been shown by Bongaarts and Feeney (1998) that upward or downward shift in the age at child birth for each birth order can distort the period measure of fertility level, TFR, to a great extent, and thus the quantum effect cannot be estimated properly due to distortion caused by tempo effect (change in mean age at births for each parity). Since 2004, TFR has again been declining but the decline has not been uniform throughout the country.

The purpose of this study is to identify the factors that differentiate total fertility rate between the East and West areas of Bangladesh and to identify the important correlates of contraceptive use in the East and West of Bangladesh.

\section{Materials and Methods}

The study mainly used data from Bangladesh Demographic and Health Survey (BDHS) 2007 (NIPORT et al. 2009). The survey followed a stratified two-stage cluster sample design based on the 2001 census. At the first stage 361 primary sampling units (PSU) are selected consisting of 239 rural and 122 urban units with probability proportional to size (PPS). At the second stage, a random sample of households is selected from each of the PSU and all ever-married women of the selected households are interviewed by using systematic random sampling technique.

Univariate and bivariate analysis are used for descriptive measures. Bivariate relationships between dependent and the independent variables are examined using Chi square test of association. To identify the factors influencing fertility and the acceptance of family planning, binary logistic regression was carried out. Two models were estimated, in the first we estimated use of contraception (yes $=1$, no $=0$ ) and in the second model we estimated birth occurred three years preceding the survey as dependent variable and various independent (demographic, socioeconomic and program) variables. In the analysis of the model, births occurred during last three years preceding the survey is measured as dichotomous variable coded 1 if birth occurred prior to the date of interview and 0 otherwise. Logistic regression (Hosmer and Lemeshow 1989) model is used for the analysis. The coefficient in the analysis represented increase or decrease in the log 
odds of being occurrence of birth (versus not occurrence) associated with a unit or category change in an independent variable.

The mathematical model is expressed as $\operatorname{Ln}\left(\frac{p_{i}}{1-p_{i}}\right)=\beta_{0}+\beta_{1} x_{1}+\beta_{2} x_{z}+----+\beta_{n} x_{n}$

where, $P\left(Y_{i}=1\right)=p_{i}$ and $P\left(Y_{i}=0\right)=1-p_{i} ; X_{i}=$ Independent variables such as woman's demographic, socio economic and program related characteristics, $\beta_{0}=$ Intercept term of the regression model, $\beta_{\mathrm{i}}=$ Regression co-efficient of the respective variable, representing the effect or association for individual characteristics.

\section{Results and Discussion}

Univariate analysis is conducted to describe the characteristics of respondents in East and West areas of Bangladesh. As evident, average age (29 years) of respondents is the same in both the areas. Women in the East having on the average 0.6 more children than women in the West, the average level of education is the same in both areas. About $13 \%$ of the respondents in the East are found to be Hindu and Christians compared to about $9 \%$ in the West. The socio-economic data also show that the percentage of women working in the West is more than double than in the East. NGO membership is also higher in the West than in the East. Over $44 \%$ respondents from the East reported that they have electricity, while for West, it is about $40 \%$. The wealth index shows that respondents from East are relatively richer than the respondents from the West. For example, over $11 \%$ respondents are classified as the poorest in the East as against almost double (i.e. 22.2\%) in the West. Fig. 1 shows the total fertility trends in the East and West since $1993-2007$. The figure indicates that total fertility rate is maintaining downward trends constantly over the years 1996 2004 in both East and West areas. This also shows that West has already achieved replacement level fertility (i.e. 2.2) in 2007. Fig. 1 also shows the mean age at child bearing since 1993. The figure clearly demonstrates that there has been a declining trend in the mean age at child bearing since 1993. For instance, in 1993 the mean age at child bearing was over 26 years and this has decreased to about 24.7 years in 2007. Inter quartile range of child bearing age is high (2.95) for the East indicating that range of fertility is occurring high in the East than that of the West (2.73).

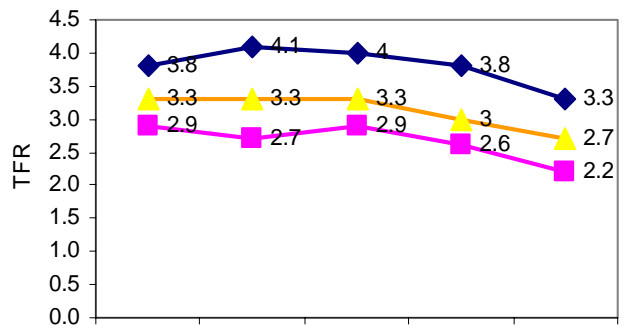

BDHS 93 BDHS 96 BDHS 99 BDHS 04 BDHS 07

$$
\rightarrow \text { East } \rightarrow-\text { West }-\_ \text {National }
$$

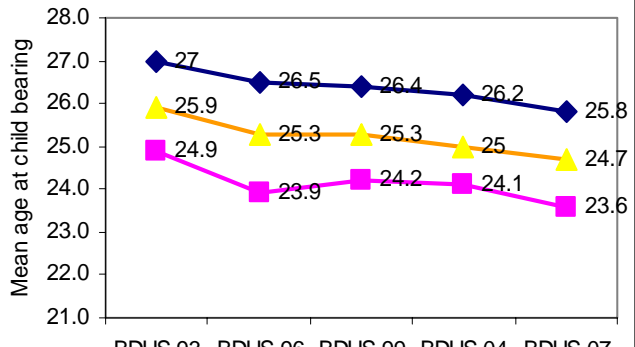

BDHS 93 BDHS 96 BDHS 99 BDHS 04 BDHS 07

$$
\rightarrow \text { East } \rightarrow-\text { West }- \text { National }
$$

Fig. 1. Total fertility and mean age at childbearing trends in East and West since 1993 - 2007. 
Age at marriage is another important proximate determinant of fertility. Early age at marriage is an important determinant of high fertility in Bangladesh. The information shows that early age at marriage is more prevalent in the West than in the East (Table 1). Over $44 \%$ of the respondents from the West were reported to be currently married by age 15 as against about $30 \%$ in the East. Similarly, by age 18 (which is the legal age at marriage) over $65 \%$ were married in the East, while for the West, the percentage was 73. The median age at marriage of adolescents in the East was one year higher than that of the West (15.0 vs 14.0 years). In the East about $24 \%$ women reported that they had no living children. The corresponding percentage in the West was about 26. Similarly, women in the East mentioned that they had on the average 2.34 living children as against an average of 1.83 in the West indicating higher fertility in the East (Table 1).

Table 1. Distribution of women age 15 - 49 by average number of living children (NLC) by East-West.

\begin{tabular}{|c|c|c|c|c|c|c|c|c|c|c|}
\hline \multirow{3}{*}{$\begin{array}{l}\text { Age } \\
\text { group }\end{array}$} & \multicolumn{5}{|c|}{ East } & \multicolumn{5}{|c|}{ West } \\
\hline & \multirow{2}{*}{$\begin{array}{c}\text { No child } \\
(\%)\end{array}$} & \multirow{2}{*}{$\begin{array}{l}\text { Mean } \\
\text { (NLC) }\end{array}$} & \multirow{2}{*}{$\begin{array}{c}\text { Proportion } \\
\text { never } \\
\text { married }\end{array}$} & \multicolumn{2}{|c|}{ Age at marriage } & \multirow{2}{*}{$\begin{array}{l}\text { No } \\
\text { Child } \\
(\%)\end{array}$} & \multirow{2}{*}{$\begin{array}{r}\text { Mean } \\
\text { (NLC) }\end{array}$} & \multirow{2}{*}{$\begin{array}{c}\text { Proportion } \\
\text { never } \\
\text { married }\end{array}$} & \multicolumn{2}{|c|}{ Age at marriage } \\
\hline & & & & Mean & Median & & & & Mean & Median \\
\hline$\overline{15-19}$ & 72.2 & 0.33 & 50.0 & 15.3 & 15 & 73.9 & 0.29 & 53.6 & 14.6 & 14 \\
\hline $20-24$ & 26.6 & 1.19 & 13.9 & 16.4 & 16 & 24.5 & 1.15 & 14.6 & 15.3 & 15 \\
\hline $25-29$ & 10.0 & 2.37 & 4.3 & 16.3 & 16 & 8.9 & 1.92 & 4.1 & 15.2 & 15 \\
\hline $30-34$ & 3.6 & 3.36 & 0.8 & 15.9 & 15 & 3.8 & 2.56 & 0.6 & 15.0 & 14 \\
\hline $35-39$ & 4.0 & 3.76 & 0.8 & 15.9 & 15 & 3.7 & 2.86 & 0.5 & 14.9 & 14 \\
\hline $40-44$ & 2.6 & 4.30 & 0.0 & 15.3 & 15 & 2.9 & 3.29 & 0.4 & 14.3 & 14 \\
\hline $45-49$ & 4.8 & 4.42 & 0.7 & 14.8 & 14 & 5.4 & 3.60 & 0.8 & 13.7 & 13 \\
\hline Total & 23.9 & 2.34 & 14.4 & 15.8 & 15 & 25.6 & 1.83 & 16.7 & 14.8 & 14 \\
\hline
\end{tabular}

The bi-variate analysis indicates that there is an association between current age, age at first marriage, and the number of living children and the current use of contraception in the East (Table 2). It is not supported in the West. In the East socio-economic characteristics such as education of the currently married women, religion, current work status, NGO membership and wealth index have significant association with current use of contraception while the association is weak in case of education and wealth index in the West. As evident from bi-variate analysis, there is a strong association between current contraceptive use status and whether and husband wife discusses about the use of contraception, desire for children and sex composition of the children in both areas (Table 3). Exposure to radio has no important effect on the current use of contraception but access to TV has significant impact on the current use of contraception $(\mathrm{p}<0.001)$. Availability of family planning services at outreach areas has significant association with current contraceptive use in the West but not in the East. Visit by family planning workers is strongly associated with current use of contraception in both East and West. Similarly, access to electricity is also associated with the current use of contraception in both areas.

Multi-variate analysis: The regression analysis revealed that, after adjusting for other variables, age, education level, religion, NGO membership, FP worker's visit, visit to the satellite 
clinic, access to electricity, desired fertility and son preference had impact on woman's current use of contraception (Table 4). Respondent's age more than 25 years are 1.3 times more likely to use contraception than the respondent's age less than 25 years in both the areas. On the other hand, variables such as availability of family planning outreach services and current work status of the respondents have no influence on the use of contraception in the East. In the West, independent variables which have no influence on current use of contraception are respondent's level of education, access to family planning outreach services, visit to satellite clinic and electricity. The sign of the regression coefficient suggests that if first birth is a son then, it increases the likelihood of current use of contraception in the East but if the first birth is a daughter then it is negatively associated with continuous use in both East and West indicating that sex preference is an important determinant of current use of contraception in Bangladesh. In the East, women with two sons are 1.9 times more likely to use contraception than women with two daughters.

Table 2. Bi-variate analysis between current contraceptive use and selected demographic characteristics by East-West.

\begin{tabular}{|c|c|c|c|c|c|}
\hline \multirow[t]{2}{*}{ Variables } & & \multicolumn{2}{|c|}{ East } & \multicolumn{2}{|c|}{ West } \\
\hline & & Percent & $\mathrm{n}$ & Percent & $\mathrm{n}$ \\
\hline \multirow[t]{2}{*}{ Age group } & $15-19$ & 24.7 & 328 & 50.5 & 555 \\
\hline & $\geq 40$ & 32.5 & 474 & 61.5 & 727 \\
\hline Chisquare and $\mathrm{p}$ value & & $\chi^{2}=89.3 ; p<0.01$ & & $\chi^{2}=124.5 ; p<0.01$ & \\
\hline \multirow[t]{2}{*}{ Age at first marriage } & $<18$ years & 38.8 & 1898 & 65.2 & 3388 \\
\hline & $\geq 18$ years & 46.7 & 613 & 63.7 & 477 \\
\hline Chi square; $p$ value & & $\chi^{2}=11.7 ; p<0.01$ & & $\chi^{2}=0.38 ; p<0.54$ & \\
\hline \multirow{3}{*}{ Number of living children } & None & 11.2 & 278 & 24.7 & 393 \\
\hline & One & 35.7 & 488 & 61.4 & 929 \\
\hline & Four or more & 46.0 & 795 & 64.2 & 646 \\
\hline Chi square; $p$ value & & $\chi^{2}=133.7 ; 0.01$ & & $\chi^{2}=377.6 ; 0.01$ & \\
\hline \multirow{2}{*}{ Level of education } & 0 & 34.9 & 845 & 65.9 & 1244 \\
\hline & $\geq 10$ & 60.5 & 129 & 63.7 & 248 \\
\hline Chi square; $p$ value & & $\chi^{2}=34.2 ; \mathrm{p}<0.01$ & & $\chi^{2}=1.4 ; p<0.69$ & \\
\hline \multirow{2}{*}{ Religion } & Islam & 39.4 & 2198 & 64.3 & 3524 \\
\hline & Others & 49.7 & 314 & 73.1 & 335 \\
\hline Chi square; $p$ value & & $\chi^{2}=11.9 ; \mathrm{p}<0.01$ & & $\chi^{2}=10.5 ; p<0.01$ & \\
\hline \multirow[t]{2}{*}{ Currently Working } & Yes & 44.5 & 447 & 70.3 & 1549 \\
\hline & No & 39.9 & 2063 & 61.5 & 2315 \\
\hline Chi square; $p$ value & & $\chi^{2}=3.3 ; p<0.07$ & & $\chi^{2}=31.5 ; p<0.01$ & \\
\hline \multirow[t]{2}{*}{ NGO membership } & Yes & 46.9 & 693 & 70.7 & 1716 \\
\hline & No & 38.4 & 1819 & 60.5 & 2150 \\
\hline Chi square; $p$ value & & $\chi^{2}=14.9 ; \mathrm{P}<0.01$ & & $\chi^{2}=43.8 ; p<0.01$ & \\
\hline \multirow[t]{2}{*}{ Wealth index } & Poorest & 30.9 & 285 & 63.7 & 857 \\
\hline & Richest & 46.0 & 520 & 67.1 & 593 \\
\hline Chi square; $p$ value & & $\chi^{2}=17.9 ; p<0.01$ & & $\chi^{2}=7.0 ; p<0.13$ & \\
\hline Total & & 40.7 & 2512 & 65 & 3864 \\
\hline
\end{tabular}

Factors influencing current fertility: The logistic regression analysis shows that the current fertility is $20 \%$ significantly less in 2007 than that in 1993 in the West (Table 5). The current fertility is significantly negatively correlated with age of the respondents, age at first marriage, 
education, access to electricity, current work status and the sex preference of the children in the East. However, religiosity and all female living children are positively associated with current fertility among respondents. The result indicates that in the West region women with all living

Table 3. Bi-variate analysis between current contraceptive use and program factors and sex composition by East-West.

\begin{tabular}{|c|c|c|c|c|c|c|}
\hline \multirow{2}{*}{\multicolumn{3}{|c|}{ Variables }} & \multicolumn{2}{|c|}{ East } & \multicolumn{2}{|c|}{ West } \\
\hline & & & Per cent & $\mathrm{n}$ & Per cent & $\mathrm{n}$ \\
\hline \multicolumn{7}{|c|}{ Husband-wife discussion about FP } \\
\hline & \multicolumn{2}{|l|}{ Yes } & 68.4 & 950 & 84.4 & 1931 \\
\hline & \multicolumn{2}{|l|}{ No } & 23.9 & 1561 & 45.6 & 1931 \\
\hline \multicolumn{3}{|c|}{ Chi square; $p$ value } & $\chi^{2}=483.2 ; \mathrm{p}$ & & $\chi^{2}=637.7 ; p$ & \\
\hline \multirow[t]{3}{*}{$\begin{array}{l}\text { Desire for } \\
\text { children }\end{array}$} & \multicolumn{2}{|c|}{$\begin{array}{l}\text { Both husband and } \\
\text { wife do not want }\end{array}$} & 41.9 & 1858 & 66.3 & 3124 \\
\hline & \multicolumn{2}{|c|}{ Husband wants more } & 39.4 & 355 & 58.3 & 290 \\
\hline & \multicolumn{2}{|c|}{$\begin{array}{l}\text { Husband wants } \\
\text { fewer }\end{array}$} & 49.0 & 153 & 68.0 & 303 \\
\hline \multicolumn{3}{|c|}{ Chi square; $p$ value } & $\chi^{2}=31.5 ; \mathrm{p}<$ & & $\chi^{2}=36.5 ; \mathrm{p}<$ & \\
\hline & \multicolumn{2}{|c|}{ No child } & 11.2 & 278 & 24.7 & 393 \\
\hline & \multicolumn{2}{|l|}{1 son } & 39.8 & 256 & 63.4 & 503 \\
\hline & \multicolumn{2}{|c|}{1 daughter } & 31 & 232 & 59 & 424 \\
\hline & \multicolumn{2}{|c|}{2 sons } & 52.1 & 219 & 74.2 & 387 \\
\hline & \multicolumn{2}{|c|}{2 daughters } & 35.4 & 161 & 69.8 & 324 \\
\hline & \multicolumn{2}{|c|}{1 son and 1 daughter } & 47.4 & 1366 & 72.7 & 1834 \\
\hline \multicolumn{3}{|c|}{ Chi square; $p$ value } & $\chi^{2}=148.8 ; p$ & & $\chi^{2}=353.1 ; p$ & \\
\hline \multirow{2}{*}{\multicolumn{2}{|c|}{ Exposure to radio }} & Yes & 40.6 & 342 & 68.1 & 502 \\
\hline & & No & 40.8 & 2170 & 64.5 & 3364 \\
\hline \multicolumn{3}{|c|}{ Chi square; $p$ value } & $\chi^{2}=0 ; p<0$ & & $\chi^{2}=2.5 ; \mathrm{p}<0$ & \\
\hline \multirow{2}{*}{\multicolumn{2}{|c|}{ Exposure to TV }} & Yes & 48.3 & 744 & 69.6 & 1192 \\
\hline & & No & 37.6 & 1768 & 62.9 & 2673 \\
\hline \multicolumn{3}{|c|}{ Chi square; $p$ value } & $\chi^{2}=24.5 ; \mathrm{p}<$ & & $\chi^{2}=16.3 ; \mathrm{p}<$ & \\
\hline \multirow{2}{*}{\multicolumn{2}{|c|}{$\begin{array}{l}\text { Family planning outreach } \\
\text { services }\end{array}$}} & Yes & 41.6 & 1607 & 65.8 & 3034 \\
\hline & & No & 39.8 & 674 & 63.7 & 586 \\
\hline \multicolumn{3}{|c|}{ Chi square; $p$ value } & $\chi^{2}=1.7 ; p<$ & & $\chi^{2}=6.5 ; p<1$ & \\
\hline \multirow{2}{*}{\multicolumn{2}{|c|}{$\begin{array}{l}\text { Field worker's visitation } \\
\text { last } 6 \text { months }\end{array}$}} & Yes & 57.5 & 386 & 81.1 & 965 \\
\hline & & No & 37.7 & 2127 & 59.6 & 2900 \\
\hline \multicolumn{3}{|c|}{ Chi square; $p$ value } & $\chi^{2}=53.1 ; p<$ & & $\chi^{2}=147.4 ; \mathrm{p}$ & \\
\hline \multirow{2}{*}{\multicolumn{2}{|c|}{ Availability of electricity }} & Yes & 46.2 & 1115 & 67.8 & 1543 \\
\hline & & No & 36.6 & 1160 & 64.8 & 2007 \\
\hline Chi square; & & & $\chi^{2}=24.6 ; p<$ & & $\chi^{2}=25.8 ; \mathrm{p}<$ & \\
\hline Total & & & 40.7 & 2512 & 65 & 3864 \\
\hline
\end{tabular}


female children are two times more likely to have given birth than women having at least one male child. In the West the variables which have influence on the current fertility are age of the respondents, age at first marriage, NGO membership, access to electricity, current work status, sex preference and current contraceptive use. All are negatively correlated with the current fertility except age at first marriage. Women with all male living children are 24 per cent less likely to have given birth than their counterpart (women having no male child) in the West. Similarly the women who are NGO workers have $17 \%$ less chance of giving birth than those who are not involved in NGO activity.

Table 4. Odd ratio from logistic regression analysis assessing the association between explanatory variables and current use of contraception.

\begin{tabular}{|c|c|c|c|c|c|c|c|}
\hline \multirow[b]{2}{*}{ Variables } & & \multicolumn{3}{|c|}{ East } & \multicolumn{3}{|c|}{ West } \\
\hline & & B & OR & $\overline{p \text { value }}$ & B & OR & $\mathrm{p}$ value \\
\hline Respondent's age (in year) & $\geq 25 ;(<25=\mathrm{RC})$ & 0.27 & 1.31 & 0.03 & 0.34 & 1.40 & 0.03 \\
\hline Age at marriage & $\geq 15 ;(<15=\mathrm{RC})$ & 0.08 & 1.08 & 0.35 & 0.04 & 1.04 & 0.58 \\
\hline \multirow[t]{4}{*}{ Educational level } & $0(\mathrm{RC})$ & & 1.00 & & & 1.00 & \\
\hline & $1-5$ & 0.28 & 1.32 & 0.02 & 0.00 & 1.00 & 0.99 \\
\hline & $6-10$ & 0.31 & 1.36 & 0.02 & -0.02 & 0.98 & 0.81 \\
\hline & $\geq 10$ & 0.94 & 2.56 & 0.00 & -0.12 & 0.89 & 0.54 \\
\hline Religion & $\begin{array}{l}\text { Islam }(\mathrm{RC}= \\
\text { Others) }\end{array}$ & -0.38 & 0.68 & 0.00 & -0.47 & 0.63 & 0.00 \\
\hline NGO member & Yes $(\mathrm{No}=\mathrm{RC})$ & 0.30 & 1.35 & 0.00 & 0.17 & 1.19 & 0.03 \\
\hline Exposure to TV & Yes $($ No $=\mathrm{RC})$ & 0.20 & 1.22 & 0.07 & 0.37 & 1.45 & 0.00 \\
\hline $\begin{array}{l}\text { Family planning outreach } \\
\text { services }\end{array}$ & Yes $($ No $=\mathrm{RC})$ & -0.05 & 0.95 & 0.63 & -0.02 & 0.98 & 0.84 \\
\hline Field worker's visit status & Yes $(\mathrm{No}=\mathrm{RC})$ & 0.62 & 1.86 & 0.00 & 0.92 & 2.51 & 0.00 \\
\hline Visit status of satellite clinic & Yes $(\mathrm{No}=\mathrm{RC})$ & 0.25 & 1.28 & 0.03 & -0.12 & 0.89 & 0.18 \\
\hline $\begin{array}{l}\text { Husband-wife communication } \\
\text { of FP }\end{array}$ & Yes $($ No $=\mathrm{RC})$ & 1.50 & 4.48 & 0.00 & 2.00 & 7.39 & 0.00 \\
\hline Electricity available & Yes $(\mathrm{No}=\mathrm{RC})$ & 0.28 & 1.32 & 0.01 & -0.01 & 0.99 & 0.95 \\
\hline Currently working & Yes $($ No $=\mathrm{RC})$ & 0.17 & 1.19 & 0.16 & 0.21 & 1.23 & 0.01 \\
\hline Desired fertility & Yes $(\mathrm{No}=\mathrm{RC})$ & -0.53 & 0.59 & 0.00 & -0.06 & 0.94 & 0.58 \\
\hline \multirow[t]{5}{*}{ Sex preference } & & & 1.00 & & & 1.00 & \\
\hline & 1 son & 0.12 & 1.13 & 0.60 & -0.44 & 0.64 & 0.01 \\
\hline & 1 daughter & -0.32 & 0.73 & 0.18 & -0.60 & 0.55 & 0.00 \\
\hline & 2 sons & 0.64 & 1.90 & 0.00 & 0.23 & 1.26 & 0.03 \\
\hline & 2 daughters (RC) & & & & & & \\
\hline Constant & & -0.70 & & & 0.71 & & \\
\hline Chi square & & 359.40 & & & 531.40 & & \\
\hline-2 Log likelihood & & 3032.50 & & & 4456.70 & & \\
\hline
\end{tabular}

$\mathrm{OR}=$ Odd ratio $\mathrm{RC}=$ Reference category 
Policy implications: The above analysis by East and West has implications for future change in the fertility and programmatic implications. Important factors that divide the East and the West are programmatic factors; socio-economic and cultural and demographic factors. Reproductive health programs should strive to encourage communication and joint decision making about contraceptives among couples desiring to space or limit births. Program should target men and in particular in the East to increase approval and support for modern contraceptives (Kamal 2000, Mannan 2002, Islam and Mahmud 1995). Efforts should also be made to increase women's confidence in their own reproductive choices, helping them to overcome negative attitude from social groups and in particular religious leaders. Age at marriage is still low and this should be increased to legal age at marriage which is 18 years. In the absence of low age at marriage women should be motivated to increase birth interval and in particular first birth interval. Teen age marriage and teen age fertility need to be socially discouraged due to high risks involved with both health and fertility.

Table 5. Odd ratio from logistic regression analysis assessing the association between explanatory variables and birth preceding three years.

\begin{tabular}{|c|c|c|c|c|c|c|c|}
\hline \multirow[t]{2}{*}{ Variables } & & \multicolumn{3}{|c|}{ East } & \multicolumn{3}{|c|}{ West } \\
\hline & & $\mathrm{B}$ & OR & $\mathrm{p}$ value & $\mathrm{B}$ & OR & $p$ value \\
\hline Age & $\geq 25 ;(<25=\mathrm{RC})$ & -1.14 & 0.32 & 0.00 & -1.60 & 0.20 & 0.00 \\
\hline Age at first marriage & $\geq 15(<15=\mathrm{RC})$ & 0.15 & 1.16 & 0.11 & 0.22 & 1.25 & 0.02 \\
\hline \multirow{4}{*}{ Educational level } & $0(\mathrm{RC})$ & & 1.00 & & & 1.00 & \\
\hline & $1-5$ & -0.22 & 0.80 & 0.00 & -0.09 & 0.91 & 0.03 \\
\hline & $6-9$ & -0.32 & 0.73 & 0.00 & -0.08 & 0.92 & 0.09 \\
\hline & $\geq 10$ & -0.37 & 0.69 & 0.00 & 0.10 & 1.11 & 0.32 \\
\hline Religion & Islam $(\mathrm{RC}=$ Others $)$ & 0.28 & 1.32 & 0.00 & -0.06 & 0.94 & 0.94 \\
\hline NGO member & Yes $(\mathrm{No}=\mathrm{RC})$ & -0.07 & 0.93 & 0.52 & -0.19 & 0.83 & 0.05 \\
\hline Exposure to TV & Yes $(\mathrm{No}=\mathrm{RC})$ & -0.17 & 0.84 & 0.17 & -0.16 & 0.85 & 0.16 \\
\hline Field worker's visit status & Yes $(\mathrm{No}=\mathrm{RC})$ & 0.08 & 1.08 & 0.57 & 0.17 & 1.19 & 0.09 \\
\hline Electricity available & Yes $(\mathrm{No}=\mathrm{RC})$ & -0.44 & 0.64 & 0.00 & -0.29 & 0.75 & 0.01 \\
\hline Currently working & Yes $(\mathrm{No}=\mathrm{RC})$ & -0.32 & 0.73 & 0.00 & -0.31 & 0.73 & 0.00 \\
\hline \multirow[t]{5}{*}{ Survey period } & BDHS 93 (RC) & & 1.00 & & & 1.00 & \\
\hline & BDHS 96 & 0.25 & 1.28 & 0.00 & 0.12 & 1.13 & 0.03 \\
\hline & BDHS 99 & 0.19 & 1.21 & 0.00 & 0.07 & 1.07 & 0.19 \\
\hline & BDHS 04 & 0.09 & 1.09 & 0.15 & -0.08 & 0.92 & 0.11 \\
\hline & BDHS 07 & -0.04 & 0.96 & 0.52 & -0.22 & 0.80 & 0.00 \\
\hline \multirow[t]{2}{*}{ Sex preference } & $\begin{array}{l}\text { All living children } \\
\text { (female) }\end{array}$ & 0.717 & 2.05 & 0.04 & 0.251 & 1.29 & 0.50 \\
\hline & $\begin{array}{l}\text { All living children } \\
\text { (male) }\end{array}$ & -0.194 & 0.82 & 0.00 & -0.27 & 0.76 & 0.00 \\
\hline Contraceptive use & Yes $(\mathrm{No}=\mathrm{RC})$ & 0.02 & 1.02 & 0.88 & 0.08 & 1.08 & 0.40 \\
\hline Constant & & 0.13 & & 0.13 & -0.37 & & \\
\hline Chi square & & 1109.8 & & & 2381 & & \\
\hline$-2 \log$ likelihood & & 16452 & & & 21436 & & \\
\hline
\end{tabular}

$\mathrm{OR}=$ Odd ratio; $\mathrm{RC}=$ Reference category.

The results suggest that son preference and religiosity are important barriers of current contraceptive use in the East side of the country. Health care providers need to be aware of 
woman's religious stance regarding the use of contraceptives and its impact on their decision to use contraceptives especially for spacing childbirth and take this into considerations when counseling women about family planning. Therefore, effective counseling should be individualized to meet the specific contraceptive needs of each woman. Counseling services could be offered during one -to-one counseling, or counseling of group of women, and/or including men in the counseling. This could also be done focusing these issues through mass media and using advocacy program among the religious leaders of the East.

The findings implied that births are occurring at a relatively lower ages in the recent surveys i.e. the births are taking place at shorter distance from the central tendency of fertility (NIPORT et al. 2009). However, the dispersion of fertility is higher in the East than that of the West. This is mainly attributed to the fact that higher order births are more prevalent in East than that of the West. A review of age at marriage pattern shows that, over the last few decades there has been a very little improvement in the age at marriage. However, although age at marriage is almost same but fertility is higher in the East than the West. Age at first marriage is not associated with the current use of contraception in the West which is possibly due to the low age at marriage. Teen age fertility is also high in the West and its contribution to the fertility is more than one fifth of the total fertility. Availability of family planning services at outreach areas has significant association with current contraceptive use in the West but not in the East. Supporting program effort is weak in the East than in the West. Considering as the dependent variable births in the three years preceding the survey, it has been observed that son preference is still an important determinant of birth control in the East i.e. women with one female child are less likely to be family planning users than women with one male child. This is particularly strong in the East than in the West.

The analysis suggests that if all the children are females then it would increase fertility in the East than in the West. In contrast, if family has one living son then it would decrease fertility and this is particularly true for the West. The findings also suggest that over the last two decades contraception has emerged as the highest fertility reducing factor in Bangladesh. Since the current use of contraception is significantly lower in the East than that of the West, this leads to the conclusion that current use of contraception divides the East and West. The other factors like access to electricity, current work status, sex preference of respondent mothers also effect on lowering fertility. It also implies that the future reduction in fertility in Bangladesh may largely depend on increased use of effective birth control methods.

\section{References}

Bongaarts, J. and G. Feeney. 1998. On the quantum and tempo of fertility. Population and Development Review, 24(2):271-291.

Caldwell, J.C., Barkat-E-Khuda, Bruce C. Caldwell, Indrani Pieris and Pat Caldwell.1999. The Bangladesh fertility decline: An interpretation. Population and Development Review 25(1):67-84.

Cleland, J. 1994. Fertility levels and trends in Bangladesh. In: J. Cleland et al. (eds.), Bangladesh fertility survey 1989, Secondary analysis, National Institute of Population Research and Training (NIPORT), Dhaka. 
Hosmer D.W. and S. Lemeshow.1989. Applied Logistic Regression. New York, John Wiley.

Islam, M., Chakroborty, N. and Rob, U. 2004. Regional Variations in Fertility in Bangladesh' Fertility Transition in Bangladesh: Evidence and Implication. Ubaidur Rob, Md. Nurul Ameen and Nancy PietPelon (eds), UNFPA, Bangladesh.

Islam M.M and M Mahmud. 1995. Contraception among adolescents in Bangladesh. Asia-Pacific Population Journal 10(1): 21-38.

Kabir, M. and Chowdhury A.A.M. 2004. Plateauing Fertility in Bangladesh: 'Correlates and proximate determinants', Fertility Transition in Bangladesh: Evidence and Implication, Ubaidur Rob, Md. Nurul Ameen and Nancy Piet-Pelon (eds), UNFPA, Bangladesh.

Kamal N. 2000. The influence of husbands on contraceptive use by Bangladeshi women. Health Policy and Planning 15 (1): 43-51.

Mannan, H.R. 2002. Factors in contraceptive method choice in Bangladesh: Goals, competence, evaluation and access. Contraception 65: 357-64

Mamun A.A., Islam, M.M. and R. Bairagi.1998. Fertility and its proximate determinants in Bangladesh: Evidence from the 1993/94 Demographic and Health Survey. Asia-Pacific Population Journal 13(3): 3-22.

National Institute of Population Research and Training (NIPORT), Mitra and Associates, and Macro International. 2009. Bangladesh Demographic and Health Survey 2007. Dhaka, Bangladesh and Calverton, Maryland, USA.

(Manuscript received on 3 September, 2012; revised on 18 May, 2013) 